\title{
Exploration of knowledge of cervical cancer and cervical cancer screening amongst HIV-positive women
}

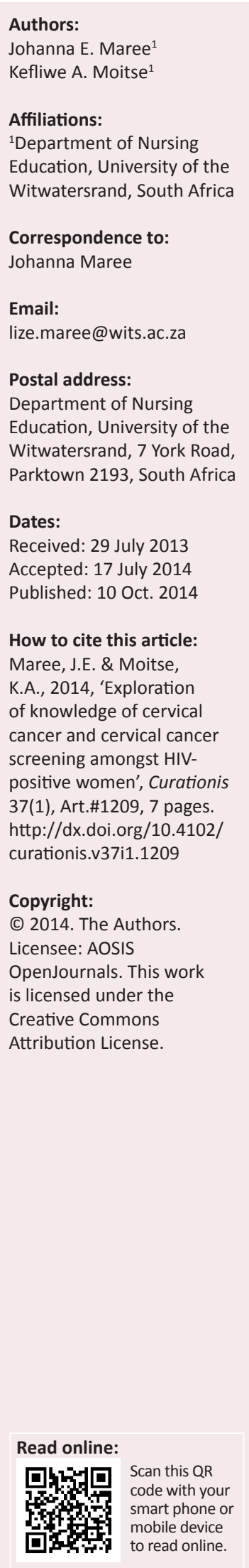

Background: Although preventable, cervical cancer, an AIDS-related disease, is the second most common cancer amongst South African women and the most common cancer amongst black women.

Objective: The objective of the study was to determine what women being treated for HIV and AIDS at a specific healthcare centre in Johannesburg knew about cervical cancer and cervical screening.

Method: A survey design was used, with data gathered by means of a self-administered questionnaire. Convenience sampling selected 315 women to participate $(n=315)$. Descriptive statistics were used to analyse the data and chi-square testing found associations between categorical variables.

Results: The majority of respondents $(78.7 \% ; n=248)$ indicated that they had heard of cervical cancer and $62.9 \%(n=198)$ knew about the Pap smear, with nurses and doctors being the primary source of information. Of the women who knew about the Pap smear, less than onethird had had a smear done, the main reason being fear of the procedure.

Conclusion: The study provided evidence that women attending the specific HIV clinic were more knowledgeable about cervical cancer and screening than those of unknown HIV status involved in previous studies. Knowledge was still at a low level, especially when their exceptionally high risk was taken into account. Once again it was found that having knowledge did not necessarily mean having had a Pap smear, which remains a huge challenge in the prevention of cervical cancer.

\section{Introduction}

Prevention of cervical cancer has previously been investigated and South African nurses have added to the body of knowledge pertaining to the prevention of this life-threatening disease (Maree \& Schmollgruber 2014). However, none of these studies focused specifically on HIVpositive women, an exceptionally vulnerable population who have an increased risk of developing and dying from cervical cancer compared to HIV- negative women (Snyman 2012:2). This study's significance lies in its aim to fill this knowledge gap.

Cervical cancer is an age-old disease which physicians were able to identify long before treatment was developed. This became evident when a number of three-bladed adjustable vaginal specula, allowing visualisation of the cervix, were found amongst the archaeological treasures of Pompeii, a city buried by the eruption of Mount Vesuvius in 79 AD. It was only in the early 1940s with the development of the Papanicolaou smear (Pap smear) that a dramatic decrease in incidence and mortality became possible (Rubin 2001:89).

Epidemiological studies identified persistent infection with human papillomavirus (HPV), specifically certain oncogenic types, as one of the risk factors for developing cervical cancer (Sankaranarayanan 2002:580; Schiffman et al. 2007: 890; Lenselink et al. 2008:103). According to the World Health Organization (WHO) (2006), 99\% of cervical cancers are caused by HPV, most commonly types 16 and 18 which are found in $70 \%$ of cervical cancers. HPV is transmitted sexually, not only by means of sexual intercourse but also skin-to-skin contact or any sexual activity involving contact with body fluids (Schiffman et al. 2007:892).

In addition, cultural norms such as early or polygamous marriages increase the risk of developing cervical cancer. Even monogamous marriages pose a risk to women living in sub-Saharan Africa, as the nature of the marriage transaction gives men exclusive sexual rights to their partners whilst women do not necessarily have the same rights and therefore face increased risks of sexually transmitted infections caused by their husband's extramarital affairs. Socio-economic factors like poverty, high parity and poor hygiene are also linked to cervical cancer (Anorlu 2008:42). 
Cervical cancer develops slowly and usually has a 10- to 20-year natural history involving lesions progressing from mild dysplasia to carcinoma. This long natural history makes cervical cancer a preventable disease (WHO 2006:37).

The relationship between AIDS and cervical cancer has been debated since cervical cancer was identified as an AIDSrelated malignancy. A South African case control study (Moodley et al. 2006) found HIV-positive women to be at an increased risk of cervical pre-cancer, but they did not have an excess risk of invasive cervical cancer. This does not seem applicable to the whole of Africa, as Tanon et al. (2012) found invasive cervical cancer to be strongly associated with HIV infection in West Africa. According to Snyman (2012:2), South African data suggest that cervical cancer appears up to 10 years earlier in HIV-positive women, and is at a more advanced stage when diagnosed and more likely to cause death compared to HIV-negative women.

Despite the fact that cervical cancer can be prevented, it is the second most common cancer in women worldwide. Each year more than 500000 women are newly diagnosed whilst approximately 250000 will die from this disease (WHO 2012). Cervical cancer is primarily a cancer of the developing world as approximately $80 \%$ of women suffering from this disease live in developing countries. However, it is not limited to these areas as it is considered to be an important public health problem in Europe, having an incidence rate of 10.6 per 100 000. Western Europe, due to better developed prevention programmes, has a lower incidence and mortality rate compared to Central and Eastern Europe (Kesic, Poljak \& Rogovskaya 2012:1423). Denny (2010:70) estimates that 78879 women living in Africa are diagnosed with cervical cancer annually, whilst causing the deaths of 61 671. In Africa various factors contribute to this situation, including competing health needs, limited human and financial resources, poorly developed healthcare systems, war and civil strife, women being uninformed and disempowered, and the nature of cytological-based screening programmes (Denny, Quinn \& Sankaranarayanan 2006:S3/72).

South Africa hosts 2 healthcare systems: $80 \%$ of the population depends on the public sector, providing cost-free health care, whilst $20 \%$ uses private health care as they are either medically insured or can pay for it (SouthAfrica.Info 2012). However, in 1999 the South African National Department of Health (Cancer Association of South Africa 2008) developed and adopted a National Cancer Control Policy which included a national programme for cervical cancer screening. The screening programme allows asymptomatic women aged 30 years and older three Pap smears with a ten-year interval in their lifetime (Department of Health 2000). The cervical screening programme is executed at district level at nurseled primary health care clinics which serve as an entrance to the public health care services (Mojaki et al. 2010:109).

Despite this policy, according to the latest figures (2005) of the South African Pathological Based Cancer Registry (National
Health Laboratory Service 2012), cervical cancer remains the second most common cancer in South African women and the most common in black women, responsible for $31 \%$ of the cancer burden in this population. Whether these figures are a true reflection of the reality is debatable, as Albrecht (2006:3) is of the opinion that the registry is an under-representation. However, in South Africa the role of the registered nurse in preventing cervical cancer is not limited to just obtaining the Pap smear, but entails prevention and health promotion through teaching and counselling individuals and groups of people, as outlined in the nursing Scope of Practice (South African Nursing Council 1984).

The goal of the cervical cancer screening programme was to screen $70 \%$ of women over the age of 30 years within 10 years of implementing the policy. However, according to Gakidou, Nordhagen and Obermeyer (2008:0864) only 20\% of the target population was screened. Not being screened has far-reaching implications, as women with microinvasive cervical cancer may not experience obvious signs and symptoms and only seek health care when symptoms appear and the disease is advanced (WHO 2002). According to Snyman (2012:2) the HIV epidemic in South Africa has had a disastrous effect on cervical cancer. Women diagnosed with HIV have been gravely disadvantaged due to the lack of a formally implemented screening strategy, as they are not routinely screened when visiting clinics which provide antiretroviral treatment (ART).

\section{Problem statement}

The research problem for this study relates to the knowledge of HIV-positive women in terms of cervical cancer and the prevention thereof. Considering nurses' health promotion and disease prevention role, the fact that more than 10 years have passed since the implementation of the South African cervical screening programme, the fact that the cervical screening programme is executed at nurse-led primary healthcare clinics and that HIV-infected women (in contrast to HIV-negative women) visit HIV clinics on a regular basis, it would be quite reasonable to expect a large percentage of HIV-infected women to know of the existence of cervical cancer and cervical screening. The purpose of the study was to determine what women being treated for HIV and AIDS at a specific healthcare centre in Johannesburg know about cervical cancer and cervical screening.

\section{Trends}

South African nurses have investigated various aspects of cervical cancer prevention. Sibiya and Grainger (2007; 2010) investigated the implementation of the National Cervical Cancer Screening Programme and the perceptions of registered nurses towards it. Maree and Wright (2007) explored possible reasons for the low screening uptake, whilst Maree (2010) investigated whether women can protect themselves from cervical cancer by insisting on the use of a condom. Men's knowledge of cervical cancer was also explored (Maree, Wright \& Makua 2011) and Maree and 
Wright (2011) investigated the preferred message promoting cervical screening. In addition, two interventions to improve cervical cancer screening uptake were tested, one combining breast and cervical cancer screening (Maree, Lu \& Wright 2012) and the other the use of a community health worker (Tum, Maree \& Clarke 2013).

\section{Research method and design Design}

A survey design (Hallberg 2008) which according to the author answers research questions where the researcher wants a broad overview of a certain situation and is suitable for investigating people's knowledge, was selected for this study.

\section{Context of the study}

The setting for this study was an adult HIV unit at a public hospital in Johannesburg, South Africa. This unit provides specialist outpatient services including counselling prior to the initiation of ART and follow-up care to people living in Johannesburg. Patient records and the registered nurses practising in the clinic facilitated the sampling process. Three hundred and fifteen women visiting the clinic for follow-up care during February and March 2011 meeting the inclusion criteria of being aged 18 years and older and already on ART were willing to participate in the study, and became the convenience-selected sample $(n=315)$. Data pertaining to the response rate were not gathered.

\section{Data gathering and data analysis}

A self-administered questionnaire developed by Hoque and Hoque (2009) was adapted to gather the data, with permission from the authors. Healthcare professionals, who are specialists in the field of HIV management, reviewed the questionnaire and guided changes to fit the specific population. The provisional version of the questionnaire was discussed with medical practitioners who specialise in the field of HIV management to determine whether this version would be sufficiently comprehensive in seeking the proper range of responses and would be suitable for the target population. The experts were satisfied that the provisional version covered the topic investigated, whereafter the questionnaire was finalised. According to Polit and Beck (2010:378) there is no totally objective method to ensure adequate content coverage of any data collection instrument. However, using an existing questionnaire and adapting it with the assistance of experts maintained the content validity and reliability of the instrument.

The questionnaire, written in English, contained 18 closedended questions organised into three sections. Section A gathered demographic and contraceptive use data, section $\mathrm{B}$ cervical cancer knowledge and section $\mathrm{C}$ knowledge of cervical cancer screening. The questionnaire was pretested using 20 women in the study setting, leading to correction of only a typographical error. The data obtained during the pretest were not included in the study data.

Women who were selected for the study were approached in the waiting area of the clinic after being registered in the unit register. Counsellors trained and supervised by the second author, working in the unit, assisted with the gathering of the data, language issues, answering of questions and management of emotional discomfort. The data were entered onto an Excel spreadsheet and analysed using descriptive statistics. The Chi-square test was used to find an association between categorical variables.

\section{Results}

Respondents were primarily single and young, with ages varying between 27 and 54 years; the average age was 38.9 years. Only 3.2\% $(n=10)$ indicated that they used oral contraceptives, whilst the majority $(92.1 \% ; n=290)$ reported they used condoms. However, condoms were not used every time respondents had sexual intercourse, as $18.1 \%(n=57)$ indicated not doing so. Only $1.6 \%(n=5)$ reported that they smoked. The general characteristics of the respondents are presented in Table 1.

Half of the women $(50.5 \%, n=159)$ who indicated using condoms every time they had sexual intercourse were aged 40 years and older. Fewer respondents $(43.2 \% ; n=156)$ younger than 40 years reported similar behaviour. A greater percentage of unmarried women, either single or divorced $(41.3 \%, n=130)$ used condoms every time they had sexual intercourse compared to married women $(32.9 \% ; n=103)$. There was a significant association between condom use with each sexual intercourse act and age $\left(\chi^{2}=28.01 ; p=0.0000\right)$ and marital status $\left(\chi^{2}=3.25 ; p=0.0712\right)$.

The majority of respondents $(78.7 \% ; n=248)$ indicated that they had heard of cervical cancer, whilst $21.3 \%(n=67)$ had never heard of it. A higher percentage of women aged 40 years and older indicated not knowing about cervical cancer compared to those younger than 40 years (22.6\% vs. $19.9 \%$ ). The age group 40-49 years had the highest percentage of respondents $(24.1 \% ; n=35)$ not knowing about cervical cancer. There was however no association between age and knowledge of cervical cancer $\left(\chi^{2}=0.36 ; p=0.5481\right)$.

TABLE 1: General characteristics of the respondents $(n=315)$.

\begin{tabular}{lll}
\hline Characteristic & $\boldsymbol{n}$ & $\mathbf{\%}$ \\
\hline Age (yrs) & 5 & \\
$20-29$ & 151 & 4.6 \\
$30-39$ & 145 & 47.9 \\
$40-49$ & 14 & 4.4 \\
$50-59$ & & \\
Marital status & 159 & 50.5 \\
Single & 139 & 44.1 \\
Married & 17 & 5.4 \\
Divorced & & \\
Oral contraceptive use & 10 & 3.2 \\
Yes & & \\
\hline
\end{tabular}


Health professionals (nurses and doctors) mostly informed respondents about the existence of cervical cancer $(61.0 \%$; $n=192)$, followed by classmates $(9.8 \% ; n=31)$. The most well-known risk factor for cervical cancer was having more than one sex partner $(19.0 \% ; n=60)$, followed by smoking $(7.9 \% ; n=25)$. More than $15 \%(16.5 \% ; n=52)$ of respondents indicated they did not know the cause of cervical cancer (Table 2); one-third $(34.6 \% ; n=109)$ reported knowing that cervical cancer was a preventable disease, whilst $65.4 \%$ were unaware of this.

More than half of the respondents $(62.9 \% ; n=198)$ indicated they had heard of the Pap smear, whilst 36.8\% $(n=116)$ were unaware of the existence of this screening test; one participant $(0.3 \%)$ did not answer the question. Women aged 40 years and older were slightly more knowledgeable about the Pap smear compared to younger women $(64.8 \%$ vs. $61.3 \%$ ). The group between the ages $30-39$ years had the highest percentage of not knowing about the Pap smear $(18.7 \% ; n=59)$, followed by those aged $40-49$ (15.6\%; $n=49)$. There was a significant association between age and knowledge of the Pap smear $\left(\chi^{2}=0.41 ; p=0.5218\right)$. Once again nurses and doctors informed most of the respondents $(57.1 \% ; n=180)$ about this screening test (Table 3$)$.

Less than one-third of the women who knew about the Pap smear $(31.8 \% ; n=63)$ had had one; most $(55.5 \% ; n=35)$ were between the ages of 40 and 49 years. All those who had had a Pap smear $(100 \% ; n=63)$ reported using condoms every time they had sexual intercourse. A greater percentage of unmarried women reported using Pap smear screening compared to married women $(57.1 \%$ vs. $42.9 \%)$. Most of the respondents who reported having had a Pap smear $(81.0 \%$; $n=51$ ) said they knew the results of their screening test, whilst $19.0 \%(n=11)$ did not.

Upon asking those who knew about the existence of the Pap smear but did not use the screening opportunity

TABLE 2: Sources of information and knowledge of the risks of cervical cancer $(n=315)$.

\begin{tabular}{lll}
\hline Criteria & $\boldsymbol{n}$ & $\mathbf{\%}$ \\
\hline Sources of information about the existence of cervical cancer* & \\
Parents & 7 & 2.2 \\
Classmates & 31 & 9.8 \\
Relatives & 17 & 5.4 \\
Nurse or doctor & 192 & 61.0 \\
Community health workers & 16 & 50.8 \\
Other & 17 & 5.4 \\
Risk factors of cervical cancer $\dagger$ & & \\
Do not know & 52 & 16.5 \\
Early onset of sexual intercourse & 30 & 9.5 \\
More than one sexual partner & 60 & 19.0 \\
Smoking & 25 & 7.9 \\
Family history of cervical cancer & 24 & 7.6 \\
HPV & 24 & 7.6 \\
Vulva warts & 14 & 4.4 \\
Other & 38 & 12.1 \\
\hline
\end{tabular}

$\dagger$, Respondents could select more than one option, therefore percentages might be higher than $100 \%$. why they never had a Pap smear done $(n=135)$, the most common answer was fear of the procedure $(39.3 \% ; n=53)$. No participant indicated cultural or religious prescriptions prevented them from having this screening test. When asked what the Pap smear was used for, $\operatorname{most}(66.7 \% ; n=90)$ indicated that it detected cervical cancer, whilst $10.4 \%$ were of the opinion that it prevented cervical cancer. No respondents thought a Pap smear detected other forms of cancer or was used to treat infertility (Table 3 ). Women aged 40 years and older were slightly more knowledgeable about the Pap smear being used to detect cervical cancer than those who were younger (53.2\% vs. $47.7 \%$ ).

Upon asking respondents who had heard of the Pap smear $(n=198)$ when a woman should have a Pap smear for the first time, more than half $(54.5 \%, n=108)$ indicated the correct age of 30 years; $6.6 \%(n=13)$ said they did not know, whilst the rest $(38.9 \% ; n=77)$ selected incorrect answers. Only a small percentage $(5.1 \% ; n=10)$ knew that a Pap smear should be done every 10 years; the biggest percentage $(48.5 \%$; $n=96)$ indicated each year, whilst the rest either did not know $(34.3 \% ; n=68)$ or chose incorrect answers $(12.1 \% ; n=24)$. Similarly, only a small percentage $(4.5 \% ; n=9)$ knew that women are supposed to have 3 Pap smears in a lifetime; the most popular answer was 10 times in a lifetime $(34.3 \% ; n=98)$. Only 7 respondents had knowledge of all 3 determinants of screening: 2 were younger than 40 years and 5 were aged 40 and older. Table 4 presents the detail of respondents' knowledge of the Pap smear.

\section{Ethical considerations}

The study was approved by the Human Research Ethics Committee (Medical) of the University of the Witwatersrand

TABLE 3: Information pertaining to the Pap smear.

\begin{tabular}{lll}
\hline Criteria & $\boldsymbol{n}$ & $\mathbf{\%}$ \\
\hline Sources of information about existence of the Pap smear $(\boldsymbol{n}=\mathbf{1 9 8})$ & \\
Friend & 6 & 1.9 \\
Family member & 1 & 0.3 \\
Nurse or doctor & 180 & 57.1 \\
Community health worker & 3 & 1.0 \\
Media & 8 & 2.5 \\
Reasons for never having had a Pap smear done $(\boldsymbol{n}=\mathbf{1 3 5})$ & \\
No answer & 5 & 3.7 \\
Fear of the procedure & 53 & 39.3 \\
Cultural and/or religious reasons & 0 & 0 \\
Not ill so not necessary & 10 & 7.4 \\
Bad attitude of nurses and doctors & 11 & 8.1 \\
Discouraged by partner or others & 0 & 0 \\
No access to a clinic where Pap smears are done & 0 & 0 \\
Other & 60 & 44.4 \\
What the Pap smear is used for ( $\boldsymbol{n}=\mathbf{1 3 5})$ & & \\
No answer & 1 & 0.7 \\
Cleaning the womb & 6 & 4.4 \\
Treatment for a sexually transmitted infection & 6 & 4.4 \\
Treatment for infertility & 0 & 0 \\
Detection of cervical cancer & 90 & 66.7 \\
Prevention of cervical cancer & 14 & 10.4 \\
Detection of other forms of cancer & 0 & 0 \\
Other & 37 & 27.3 \\
\hline
\end{tabular}


and permission to conduct it was obtained from the hospital. Those recruited were introduced to the study and given an information sheet outlining the benefits, time required to complete the questionnaire, procedure involved, measures to ensure confidentiality and anonymity and volunteerism. Before being given the questionnaire, informed consent was obtained from those willing to participate. Questionnaires were numbered sequentially and kept separate from informed consent forms to protect anonymity.

\section{Discussion}

This sample of women does not seem to be representative of HIV-positive women in South Africa in terms of age. According to Connolly et al. (2008:776) women between the ages of 20 to 29 years represent the greatest proportion of those who are HIV-positive, followed by the 30-39 and 40-49 age groups. The slight difference in terms of marital status and being HIV-positive found in this study is supported by Shisana et al. (2008:537), who state that the risk for being infected with HIV is higher amongst unmarried people.

In terms of cervical cancer prevention, the high percentage of women who reported using condoms each time they have sexual intercourse is positive. What is of concern is that it is primarily women of 40 years and older who reported this behaviour, leaving younger women more exposed not only to HIV but also to HPV. It might not be unreasonable to expect total adherence to condom use when HIV-positive. However, for women condom use is not a simple matter as this behaviour is commonly decided by men. Not all men are prepared to use condoms and women are unable to negotiate condom use due to being financially dependent on the partner, physically abused, helpless and fearful of asking them (Maree 2010).

TABLE 4: Women's knowledge of the Pap smear $(n=198)$.

\begin{tabular}{lll}
\hline Criteria & $\boldsymbol{n}$ & $\mathbf{\%}$ \\
\hline When a woman should have her Pap smear & 13 & 6.6 \\
Do not know & 4 & 2.0 \\
When menstruation starts & 1 & 0.5 \\
As soon as sexually active & 7 & 3.5 \\
When start having children & 108 & 54.5 \\
At the age of 30 & 2 & 1.0 \\
After the menopause & 16 & 8.1 \\
Other & & \\
How often a woman should have a Pap smear & 68 & 34.3 \\
Do not know & 1 & 0.5 \\
No answer & 96 & 48.5 \\
Once every year & 8 & 4.0 \\
Once every 2 years & 7 & 3.5 \\
Once every 3 years & 10 & 5.1 \\
Once every 10 years & 8 & 4.0 \\
Once in a lifetime & 1 & \\
Number of Pap smears a woman should have in her lifetime & \\
At least 1 & 45 & 22.7 \\
At least 3 & 9 & 4.5 \\
At least 5 & 98 & 0.5 \\
At least 10 & 45 & 49.5 \\
Other & 22.7 \\
\hline
\end{tabular}

The high percentage $(78.7 \%)$ of respondents knowing about the existence of cervical cancer is encouraging. This percentage compares positively to the $42.9 \%$ of South African university students who knew about the existence of cervical cancer found by Hoque and Hoque (2009:22) and the 4.7\% of women living in a specific resource-poor community in Tshwane (Maree et al. 2012:81). It was also encouraging to find that $61 \%$ of the women knowing of the existence of cervical cancer were informed by a nurse or a doctor; this percentage also compared favourably to the $19.9 \%$ found by Hoque and Hoque (2009:22). It is unknown whether respondents received this information from a nurse or doctor practising at the specific HIV clinic, but it seems that attending this clinic led to greater knowledge of the existence of cervical cancer. This is, however, mere speculation and needs evidence in order to conclude it is indeed the case.

Knowledge of the risk factors of cervical cancer was generally poor, as less than $20 \%$ of the women were able to link the risks to cervical cancer. Even less knew that HPV is a risk factor, which compares negatively to the $48.5 \%$ of university students who did know that it was (Hoque \& Hoque 2009:22). Although HPV was not a well-known risk, it was interesting to find that multiple sex partners was the most known risk factor, whereas HPV was the most known risk factor amongst university students (Hoque \& Hoque 2009:22) and early sexual debut in women living in two townships in Tshwane (Maree \& Wright 2007:59).

It was positive to find more than $60 \%$ of respondents knew of the existence of the Pap smear and knew why it is done, and that most were informed by a nurse or doctor. These findings compare positively to the $41.9 \%$ of university students who knew of the existence of the Pap smear, the 38\% who knew what the Pap smear is used for (Hoque \& Hoque 2009:22) and the $47.5 \%$ informed by a registered nurse practising in a primary health clinic (Fonn et al. 2002:152). Interestingly, the media played a very small role in informing the women in the current study about the Pap smear, as $42 \%$ of respondents in the national study of Fonn et al. (2002:152) reported having been informed by an advertisement, a campaign or the radio. In addition, it was positive to find that more than $50 \%$ of participants knew when a woman should have her first Pap smear. Being under the impression that a Pap smear should be done on an annual basis is not necessarily negative, and can easily be corrected once a Pap smear is done.

What is of great concern is that $80 \%$ of the women investigated had never had a Pap smear, which is only slightly better than the $86.6 \%$ of Gauteng women who had never had one (Fonn et al. 2002:152), and certainly not desirable when facing such a high risk. However, knowing about the Pap smear but not having one done is not uncommon behaviour, and is also not limited to women forming part of the general public. Yaren et al. (2008:281) report a similar trend amongst nurses practising in a rural region of Turkey and (Obeidat, Amarin \& Alzaghal [2012:274]) in healthcare workers in Jordan. In addition, the study provides evidence that fear of the 
Pap smear was the single most common barrier to cervical screening. This finding is supported by Hoque and Hoque (2009:23), who reported a similar trend amongst university students. Logan and McIlfatric (2011:725), in a qualitative study exploring knowledge, attitudes and experiences of women living in Northern Ireland pertaining to cervical cancer screening, also found women had negative attitudes and experienced the procedure as frightening, embarrassing and stigmatising.

\section{Limitations of the study}

Various limitations are applicable to this study. Firstly, the study was conducted in one HIV clinic at a tertiary hospital serving people from a large city, and the findings therefore cannot represent rural communities. As already mentioned, the sample did not represent the age profile of HIV-positive women in South Africa, with the age group younger than 30 years being under-represented. The findings could have been more positive if the sample represented the HIV-positive population, as according to Pillay (2002) younger women are more knowledgeable about cervical cancer. Due to the selfreporting nature of the study, recall and social desirability bias might also have been possible. By adding this study to the existing work, additional investigations of knowledge would seem to be a repetition of what is already known, and therefore future research should preferably focus on ways to improve knowledge of cervical cancer, limiting the barriers to screening uptake, and testing interventions focused on screening uptake.

\section{Recommendations}

Although women's knowledge of cervical cancer and cervical screening in this study compares positively with those in other similar work, knowledge levels are still low, especially if the added risk of being HIV-positive is considered. It may be unfair to remind nurses of their health promotion and disease prevention role, as there is no evidence that those who did not have an acceptable level of knowledge were not informed. However, it might increase levels of knowledge if nurses make a concerted effort to teach women about cervical cancer and cervical screening and assess levels of knowledge and understanding afterwards. In addition, a concerted effort to formally refer women for screening and following up whether this opportunity was used might increase screening uptake.

\section{Conclusion}

The study provided evidence that women attending the specific HIV clinic were more knowledgeable about cervical cancer and cervical cancer screening compared to women of unknown HIV status involved in previous studies. However, knowledge was still low, especially if the high risk of HIVpositive women is taken into account. It was once again found that having knowledge does not necessarily mean having had a Pap smear done, which remains a huge challenge in the prevention of cervical cancer.

\section{Acknowledgements}

The authors would like to thank E. Hogue and M. Hogue for granting permission for the use of the questionnaire and Dr J.M. Mathibe-Neke for her input in this study.

\section{Competing interests}

The authors declare that they have no financial or personal relationship(s) that may have inappropriately influenced them in writing this article.

\section{Authors' contributions}

K.M. (University of the Witwatersrand) was the project leader and responsible for gathering the data and reviewing the manuscript. J.M. (University of the Witwatersrand) analysed the data and wrote the manuscript.

\section{References}

Albrecht, C., 2006, Overview of the South African cancer research environment as a basis for discussions concerning the activation of CARISA (Cancer Research Initiative of South Africa), CARISA, Cape Town.

Anorlu, R., 2008, 'Cervical cancer: The sub-Saharan African perspective', Reproductive Health Matters 16(32), 41-49. http://dx.doi.org/10.1016/S09688080(08)32415-X

Cancer Association of South Africa, 2008, Position statement on cancer of the cervix, viewed 02 November 2009, from http://www.cansa.org.za/cgi-bin/giga. cgi?cmd $1 / 4$ cause_dir_news_item\&news_id $1 / 431883 \&$ cause_id $11 / 41056$

Connolly, C., Colvin, M., Shisana, O. \& Stoker, D., 2008, 'Epidemiology of HIV in South Africa - results of a national, community-based survey', South African Medical Journal 94(9), 776

Denny, L., 2010, 'Cervical cancer in South Africa: An overview of current status and prevention strategies', Continuing Medical Education 28(2), 70-73.

Denny, L., Quinn, M. \& Sankaranarayanan, R., 2006, 'Chapter 8: Screening for cervical cancer in developing countries', Vaccine 24(S3), S3/71-S3/77.

Department of Health, 2000, National guidelines for cervical cancer screening programme, Government Printers, Pretoria.

Fonn, S., Bloch, B., Mabina, M., Carpenter, S., Cronje, H., Maise, C., Bennun, M., Toit, G.D., De Jonge, E. \& Manana, I., 2002, 'Prevalence of pre-cancerous lesions and cervical cancer in South Africa-a multicentre study', South African Medical Journal 92(2), 148-156.

Gakidou, E., Nordhagen, S. \& Obermeyer, Z., 2008, 'Coverage of cervical cancer screening in 57 countries: Low average levels and large inequalities', PLoS Med 5(6), e132:0863-0868.

Hallberg, I., 2008, 'Surveys', in R. Watson, H. McKenna, S. Cowman \& J. Keady (eds.) Nursing research. Designs and methods, Churchill Livingstone, Edinburgh.

Hoque, E. \& Hoque, M., 2009, 'Knowledge of and attitude towards cervical cancer among female university students in South Africa', Southern African Journal of Epidemiology and Infection 24(1),21-24.

Kesic, V., Poljak, M. \& Rogovskaya, S., 2012, 'Cervical cancer burden and prevention activities in Europe', Cancer Epidemiology Biomarkers \& Prevention 21(9), 14231433. http://dx.doi.org/10.1158/1055-9965.EPI-12-0181

Lenselink, C., Gerrits, M., Melchers, W., Leon, F., Massuger, L., Van Hamont, D. \& Bekkers, R., 2008, 'Parental acceptance of Human Papillomavirus vaccines', European Journal of Obstetrics \& Gynecology and Reproductive Biology 137, 103-107. http://dx.doi.org/10.1016/j.ejogrb.2007.02.012

Logan, L. \& Mcllfatrick, S., 2011, 'Exploring women's knowledge, experiences and perceptions of cervical cancer screening in an area of social deprivation', European Journal of Cancer Care 20(6), 720-727. http://dx.doi.org/10.1111/ j.1365-2354.2011.01254.x

Maree, J., 2010, "'No condom no sex": Easy to say but not possible for all South African women', Health South African Gesondheid 15(1) Art. \#506, 8 pages.

Maree, J. \& Schmollgruber, S., 2014, 'An integrative review of the South African cancer nursing research 2002-2012', Curationis 37(1):e1-e10. http://dx.doi. org/10.4102/curationis.v37i1.1193

Maree, J. \& Wright, S., 2007, 'Sexual and menstrual practices: risks for cervix cancer', Health SA Gesondheid 12(3), 55-65. http://dx.doi.org/10.4102/hsag.v12i3.265

Maree, J. \& Wright, S., 2011, 'Cervical cancer: Does our message promote screening? A pilot study in a South African context', European Journal of Oncology Nursing 15(2), 118-123. http://dx.doi.org/10.1016/j.ejon.2010.06.008

Maree, J., Lu, X. \& Wright, S., 2012, 'Combining breast and cervical screening in an attempt to increase cervical screening uptake. An intervention study in a South African context', European Journal of Cancer Care 21(1), 78-86. http://dx.doi. org/10.1111/j.1365-2354.2011.01292.x 
Maree, J., Wright, S. \& Makua, T., 2011, 'Men's lack of knowledge adds to the cervical cancer burden in South Africa', European Journal of Cancer Care 20(5), 662-668. cancer burden in South Africa', European Journal of Can
$\mathrm{http}: / / \mathrm{dx}$.doi.org/10.1111/j.1365-2354.2011.01250.x

Mojaki, M., Basu, D., Letskokgohka, M. \& Govender, M., 2010, 'Referral steps in district health system are side-stepped', South African Medical Journal 101(2), 109.

Moodley, J., Hoffman, M., Carrara, H., Allan, B., Cooper, D., Rosenberg, L., Denny, L., Shapiro, S. \& Williamson, A., 2006, 'HIV and pre-neoplastic and neoplastic lesions of the cervix in South Africa: a case-control study', BMC Cancer 6(1), 135. http:// dx.doi.org/10.1186/1471-2407-6-135

National Health Laboratory Service, 2012, Cancer statistics, viewed 12 June 2013 from http://www.nioh.ac.za/?page=cancer_statistics\&id=163

Obeidat, B., Amarin, Z. \& Alzaghal, L., 2012, 'Awareness, practice and attitude to cervical Papanicolaou smear among female health care workers in Jordan', European Journal of Cancer Care 21(3), 372-376. http://dx.doi.org/10.1111/ j.1365-2354.2011.01297.x

Pillay, A., 2002, 'Rural and urban South African women's awareness of cancer of the breast and cervix', Ethnicity \& Health 7(2), 10-114. http://dx.doi org/10.1080/1355785022000038588

Polit, D. \& Beck, C., 2010, Essentials of nursing research: Appraising evidence of nursing practice, Wolters Kluver, Philadelphia.

Rubin, S., 2001, 'Cervical cancer: successes and failures', CA: A Cancer Journal for Clinicians 51(2), 89-91. http://dx.doi.org/10.3322/canjclin.51.2.89

Sankaranarayanan, R., 2002, 'Cervical cancer in developing countries', Transactions of the Royal Society of Tropical Medicine and Hygiene 96(6), 580-585. http://dx.doi. org/10.1016/S0035-9203(02)90317-2

Schiffman, M., Castle, P., Jeronimo, J., Rodriguez, A. \& Wacholder, S., 2007, 'Human papillomavirus and cervical cancer', The Lancet 370(8590), 890-907. http:// dx.doi.org/10.1016/S0140-6736(07)61416-0

Shisana, O., Zungu-Dirwayi, N., Toefy, Y., Simbayi, L., Malik, S. \& Zuma, K., 2008 'Marital status and risk of HIV infection in South Africa', South African Medical Journal 94(7), 537
Sibiya, N. \& Grainger, L., 2007, 'An assessment of the implementation of the provincial cervical screening programme in selected primary health care clinics in the llembe region, KwaZulu-Natal', Curationis 30(1), 48-55.

Sibiya, N. \& Grainger, L., 2010, 'Registered nurses' perceptions of the cervical screening programme in primary health care clinics in the KwaZulu-Natal province of South Africa', Curationis 12(1), 15-26. http://dx.doi.org/10.4102/curationis.v30i1.1050

Snyman, L., 2012, 'Prevention of cervical cancer-how long before we get it right?', South African Journal of Obstetrics and Gynaecology 19(1), 2-3.

SouthAfrica.Info, 2012, Health care in South Africa, viewed 11 February 2012, from http://www.southafrica.info/about/health/health.htm

South African Nursing Council, 1984, Scope of Practice, viewed 11 February 2013, from http://www.sanc.co.za/regulat/Reg-scp.htm

Tanon, A., Jaquet, A., Ekouevi, D., Akakpo, J., Adoubi, I., Diomande, I., Houngbe, F., Zannou, M., Sasco, A. \& Eholie, S., 2012, 'The spectrum of cancers in West Africa: Associations with Human Immunodeficiency Virus', PLoS One 7(10), e48108. http://dx.doi.org/10.1371/journal.pone.0048108

Tum, S., Maree, J. \& Clarke, M, 2013, 'Creating awareness and facilitating cervical and breast cancer screening uptake through the use of a community health worker: A pilot intervention study', European Journal of Cancer Care 22(1), 107-116. http:// dx.doi.org/10.1111/ecc.12005

World Health Organization, 2002, National cancer control programmes: Policies and managerial guidelines, World Health Organization, Geneva.

World Health Organization, 2006, Comprehensive cervical cancer control: A guide to essential practice, World Health Organization, Geneva.

World Health Organization, 2012, Cancer of the cervix, viewed 04 December 2012, from http://www.who.int/reproductivehealth/topics/cancers/en/

Yaren, A., Ozkilinc, G., Guler, A. \& Oztop, I., 2008, 'Awareness of breast and cervical cancer risk factors and screening behaviours among nurses in rural region of Turkey, European Journal of Cancer Care 17(3), 27-284. http://dx.doi. org/10.1111/j.1365-2354.2007.00856.x 